\title{
Designing Adaptive Artificial Agents for an Economic Production and Conflict Model
}

\author{
Behrooz Hassani-M and Brett W. Parris \\ Department of Econometrics and Business Statistics, \\ Monash University, VIC 3800, Australia \\ \{Behrooz.Hassani.Mahmooei, Brett.Parris\}@buseco.monash.edu.au
}

\begin{abstract}
Production and conflict models have been used over the past 30 years to represent the effects of unproductive resource allocation in economics. Their major applications are in modelling the assignment of property rights, rentseeking and defense economics. This paper describes the process of designing an agent used in a production and conflict model. Using the capabilities of an agent-based approach to economic modelling, we have enriched a simple decision-maker of the kind used in classic general equilibrium economic models, to build an adaptive and interactive agent which uses its own attributes, its neighbors' parameters and information from its environment to make resource allocation decisions. Our model presents emergent and adaptive behaviors than cannot be captured using classic production and conflict agents. Some possible extensions for future applications are also recommended.
\end{abstract}

Keywords: Production and Conflict Models, Agent-based Modelling, Adaptive Behavior.

\section{Introduction}

According to classic economic theories, self-interested economic agents allocate their resources for production and acquiring wealth. But empirical evidence shows that economic agents also have options to allocate their resources unproductively. Unproductive activities like theft, piracy, predation and unmerited lobbying for special treatment, do not increase the total wealth of society but instead transfer economic products and rights artificially from one agent to the other. In the last three decades, different models have been suggested to study unproductive allocations, which can be categorized in two main groups: Production and Conflict (P\&C) models and RentSeeking models [1]. In this paper we chiefly concentrate on the $\mathrm{P} \& \mathrm{C}$ models.

The main component of any $\mathrm{P} \& \mathrm{C}$ model is an economic agent who can allocate its resources to productive or unproductive activities. This kind of agent was proposed in two papers by Hirshleifer [2,3] and then developed further during 1990's and early 2000's in different studies [4-11]. More recent papers have mainly focused on using the $\mathrm{P} \& \mathrm{C}$ model to analyze the assignment of property rights [12-15].

In almost all of these models an agent can allocate its resources to three main activities: production, predation and protection (sometimes called 3P). Production means that the agent uses its resources to produce goods or services. Output is 
governed by a production function which is usually similar for all agents. Predation is the process of appropriating other agents' belongings (resources, output, wealth or any combination of them). Agents have a predation technology which governs the effectiveness of resources allocated to predation. Finally, protection is the process of defending against possible predation by providing defenses.

In this paper, we first review the structure of classic P\&C decisions. Then in section three we introduce our agent describing its attributes and procedures. In the last section we present some results from our agent implementation in a real model and offer some possible extensions and applications for the designed agent.

\section{Classic P\&C Decision}

In order to explain the motivation for designing an artificial agent for P\&C models, we first describe the attributes and procedures of agents found in classical equation-based models. It is worth mentioning that before being studied in economics, these models were considered in biology. For example Smith and Price [16] used a computer simulation to model conflict among animals using five strategies titled "Mouse", "Hawk", "Bully", "Retaliator" and "Prober-retaliator" after animal behaviors.

In economics, Hirshleifer's seminal work [2] presented a two-party interaction for the first time where agents had "two alternatives ways for generating income: (1) "peaceful" production and exchange, versus (2) "appropriative" efforts designed to seize resources previously controlled by others (or to defend against such invasions)." Later, a new aspect was added to the structure which was the possibility of protection against attacks, which led to a "3P" framework including Production, Predation and Protection options. Anderton [17] added "trade" as an option, but for simplicity, we neglect that alternative in this paper.

In addition to the possible choices, the sequence of allocations is important as well. Models can be categorized into two groups according to the arrangement of their allocation decisions: 1) parties make their decisions simultaneously, which usually happens when they make their decisions independently $[5,12,18]$ or 2) parties make their decisions sequentially, and defensive decisions are made first $[15,19]$.

Reviewing different 3P models, it can be seen that although the analysis has been extended and improved, two main problems remained unsolved. Firstly, agents need to choose between predator or producer/protector strategies. In other words, due to the limitations in general-equilibrium modelling, authors have not been able to build a player which is able to allocate resources to all three options at the same time. Modelers have always studied the $\mathrm{P} \& \mathrm{C}$ behavior at a meso-level, avoiding the consideration of micro-behavior of individual agents and instead studying their aggregate decision outputs. Secondly, agents' strategies are fixed or limited. For example in two-player predator/prey conflicts, which usually happen in one round, there is no chance for a player to switch its strategy during the running time. Only in a two player/role game like [20] can agents switch between cooperation and anticipation which leads to four different states based on a Hobessian structure. In two or more player generalequilibrium models the ratio of predators to producers is usually governed by a single exogenous variable. This is in contrast to theory and empirical evidence [21] that the desirability of being a predator or a producer is an endogenous function of the population of each group. 
The second issue in classic P\&C models is that agents are homogeneous in their characteristics. For example they have the same productivity and similar predation ability. This follows from the widespread use of representative agents in economic modelling which can give quite misleading results. For instance, we know that in a real-world perspective, one of the reasons that people become thieves is the lack of adequate production facilities. This fact has been neglected in most of the earlier studies, apart from papers like Grossman's [6] which considered this topic by adding the ratio of poorly-endowed people to well-endowed people to his model and using two new variables which indicate the productivity of each group. It should be mentioned that even in Grossman's paper, the productivity parameter is a constant, as agents' accumulated experience in their allocation does not affect their skills and return to that allocation. Muthoo [22] nominated this limitation as the first constraint in his model: "First, a simplifying but somewhat restrictive assumption that underlies my model is that the players cannot make any (further) investment in their fighting and productive skills."

The third common feature in P\&C models is that the agents have little interactive effects on each other's decisions. The only possible route for an interaction is when an agent makes a protection decision based on its opponent's predation allocation, although in models like Grossman's [6] the variable G, which stands for guarding resources, is determined exogenously. The other limitation in the interaction among agents is that classic models only concentrate on predator/producer dealings or what Anderton [17] calls "dove/hawk" interaction. Clearly though, predator/predator and producer/producer interaction is also possible and the first one in particular can affect the outcomes of the model, since there is no inherent reason why stronger predators would not target weaker predators.

Returning to the agent itself, earlier studies did not usually consider the personal characteristics of the agents. Only Grossman and Kim [23] appear to have studied the morality of agents, including moral decay and revival in $\mathrm{P} \& \mathrm{C}$ models. In other models, our player is a simple undefined person without any personal distinctive properties and preferences.

Classic P\&C models also treat information as complete and symmetric. In other words, any agent knows about all the other agents, their decisions, allocations and properties. The agent is also aware of global indicators and variables like the total number of agents, the ratio of predators to producers and so on. As we know, many of us do not know the real wealth of our close friends and relatives, their expenditures and even their monthly salaries, so this assumption is far from real world contexts.

The next common feature of classic P\&C models is the lack of evolutionary methods in their optimization and learning processes. Agents usually use simple marginal comparisons to allocate their resources in any round. But no-one wakes up every morning and calculates the marginal return for every unit of resources in order to decide daily resource allocations. Past models also do not generally make any connection between the current period and previous decisions, so agents cannot optimize their outcome using past experiences.

The final issue is the subject of the conflicts - that which is going to be predated. There are two main views: The first is that conflicts happen over an object and the second is that conflicts happen over gaining a right [24]. In this paper we mainly concentrate on the object view, though the model can be adapted to consider conflicts 
over rights too. In the object view, different models have selected different objects which become subject to predation. In some models, agents contest an insecure resource $[7,25,26]$ and in others the conflict happens over access to produced goods $[10,11]$. Kolmar [14] has reviewed both kinds of models and suggested a compound model. In his model, agents have two different resources: time, which cannot be predated, and capital which can. The last option is for predators to steal another agent's endowment. Muthoo [22] alluded to this possibility as a limitation in his P\&C model, because in current models agents cannot predate each other's production or predation technologies.

\section{Our P\&C Decision Maker}

In the last section we outlined some of the main features and limitations in designing the agents which operate in classic general-equilibrium P\&C models. In this section we try to develop a more capable and flexible agent using an agent-based modelling approach. Agent-based modelling uses an object-oriented simulation environment in which individual 'agents' posses both attributes and behaviours. Agents interact with each other dynamically according to certain rules, which may themselves evolve.

In our model agents have a life-cycle including birth, life, and death. Each agent, when born, receives an integer value as its maximum age. These integer values are distributed normally for the society and can easily be changed. For example, if we are speaking about a developed society, we can use a higher mean for our distribution compared with a model for agents in a less developed country. In this model we have assumed that our society's population growth rate is zero for simplicity, but it can also be easily changed. An agent will die if its total wealth is less than zero, which may occur after it has been predated, if it runs out of resources, or if it loses its production technology.

The second key attribute of our agent is its strategy. We present each agent's strat-

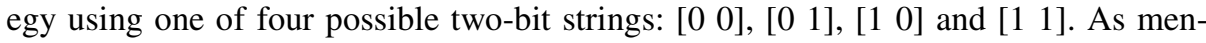
tioned in the previous section, the classic models have two main types of agents, the producer which is assigned the [0 1] strategy, and the predator, which is assigned the [1 0 ] strategy. Our producer is a moral player who will never predate the others and our predator is a pure predator who only allocates resources to predating others.

Beyond these two classic combinations however, we also have the [1 1 ] strategy used by $3 P$ agents (who can produce, predate and protect at the same time) and the $[0$ 0] strategy, which is adopted by inactive individuals. An inactive agent is one who does nothing for a specific period of time. We can think an inactive agent as someone unemployed, out of resources for either production or predation or maybe someone who is migrating to find a new place. Showing the strategy of agents by a bit pattern gives us the opportunity to use a genetic algorithm for optimizing our agents' behaviors. All agents are born with the [0 1] producer strategy.

Each agent also has a wealth variable which represents its income accumulated over time and which will be inherited by its child when the agent dies. In our model each agent has a specific spatial location, which influences the agent's productivity. It can be thought as its work place, like a farm. Each agent also has a cost of living which must be paid by the agent every time-step, which here is equal to one week, 
with a model 'year' consisting of 52 time-steps. Standard short-run processes take one week to happen. For example, agents receive their income and spend it every week. Long-run processes like changing strategy happen on a yearly basis. Our agent also has a set of control variables, like its production history, which are used for managing its processes.

Agents can be linked to one to five other agents who are close by, which give us structures like those shown in Figure 1, in a 20 by 20 spatial grid (400 places) containing 100 agents.
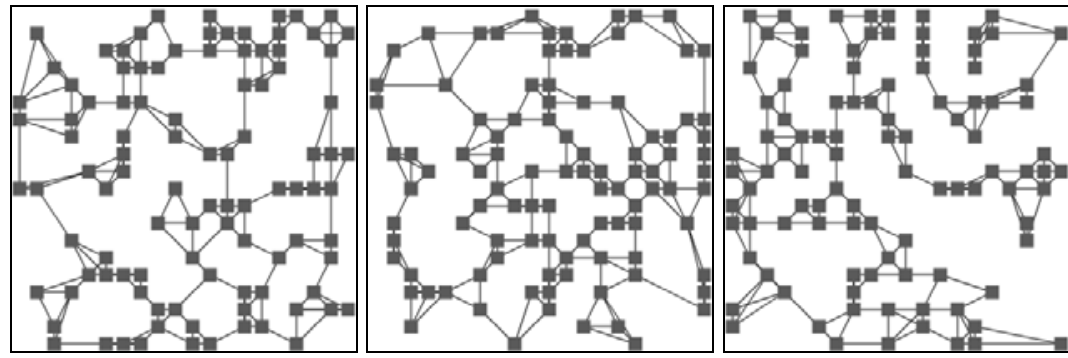

Fig. 1. Three sample arrangements of agents in our environment

In our model, information is neither complete, nor symmetric. When an agent is not linked with other agents, it means it does not know those agents at all and has no interaction with them, but when it is linked to another agent it may have some information about that other agent. Our agent cannot know all the attributes of the other agent, like its allocations, but it can partly be informed about its wealth or strategy.

Up to now, we have an agent who has its own attributes and location and it dies when it gets old or very poor. When an agent dies, a new agent is born on the same location. As discussed earlier, the new-born agent will be a producer ([ $\left.\left[\begin{array}{ll}0 & 1\end{array}\right]\right)$ by default, but before starting its activities, its strategy at birth will also interact with the strategy of its parent agent through a cross-over (as outlined in Figure 4). The probability of this cross-over for each bit is $50 \%$. Using this method we have been able to transfer the strategy from one generation to the other.

Production and predation technologies can be in any form, but we have used a simple function in the form of $f(x)=a \sqrt[b]{x}$ where $a$ and $b$ will be positive and nonzero to ensure that $f^{\prime}(x) \geq 0, f^{\prime \prime}(x) \leq 0$, thereby maintaining a direct relation between input and output and ensuring decreasing returns. The subject of the conflict can be any object, including the resources, wealth or even technology, but in order to present some new features in our model we have used the combination of wealth and production and predation technologies.

Two other issues remain: how should our agent make decisions about the allocation of its resources and how it learns from its experience in order to optimize decision process? Answering these questions form the core activity of agents, which is the allocation of resources.

At this stage, we need a new concept which can connect an agent's characteristics to its decisions, so we introduce danger to our model. Danger is a variable between zero and one, which is higher when the environment becomes more dangerous. The 
concept of danger is calculated in the same way for all agents and each agent perceives danger based on the equation below:

$$
\text { Danger }=\frac{1}{2} \sum_{t=0}^{n}(\alpha / 2)^{n-t}
$$

where $\alpha$ is 1 if the agent has been predated in the round $t$ and 0 if it has not been. So for example, if after five rounds, an agent has a thread such as $0,0,1,0,1$ which means it has been predated during the last round and the third round, its danger will be 0.3125. Danger is calculated in the same way for all agents and each agent may be predated only once during each round. Since $\sum_{1}^{n}(1 / 2)^{n}$ is always less than 2 , danger is always less than 1 . This equation reduces the effects of older experiences and limits danger to a range of $(0,1)$. To personalize this variable for our agents, we designed a simple fuzzy function. This function is determined by three values $a, b$ and $c$ as in Figure 2 below, where $a>0, a<b$, and $0<c<1$.

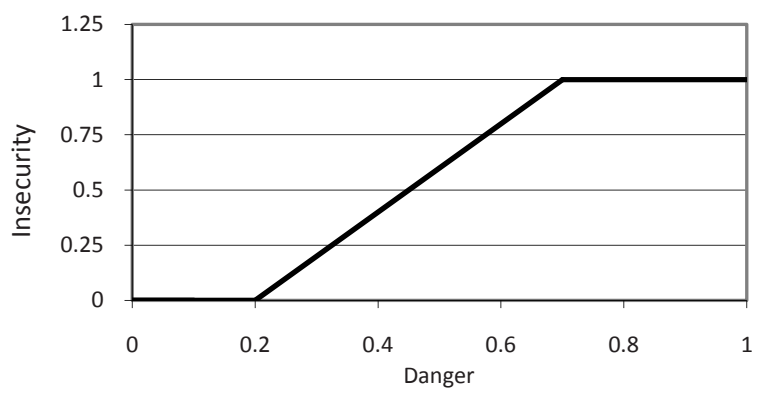

Fig. 2. A sample Danger and Insecurity Fuzzy Function

Figure 2 helps us relate agent's observations of predation to a personal interpretation of the danger which we call it insecurity. Every agent has its own $a, b$, and $c$ which are assigned when an agent is initialized by a random normal distribution. For example Figure 2 shows that when danger is less than 0.2, this agent does not have any sense of insecurity. As soon as danger becomes more than 0.2, the agent's sense of insecurity increases linearly with increasing until it reaches maximum of 1 at a danger level of 0.7 .

In Figure 3, we have shown the danger-insecurity diagram for two different agents. As can be seen, the solid line leaves the zero level at 0.2 and reaches its maximum value, 1 , when danger is 0.3 . But the dotted line increases with a shallower slope and finally it remains on 0.5 at its maximum insecurity. According to Equation 1, and using Figure 3 we can say that, if the associated agent of the first line is predated during the previous round - which will cause its danger to be at least 0.5 - it will feel completely insecure, while in the same situation the second (braver) agent's insecurity will be only 0.4 , so in this situation the first agent feel around twice as insecure as the second agent. This fuzzy function enables us to add the characteristic of "appetite for risk" to our agents, which is defined by the parameters $a, b$, and $c$.

Now, using the available features in our agent we define its allocation process. The first decision which is made by any agent is its protection. For our current agent, we 


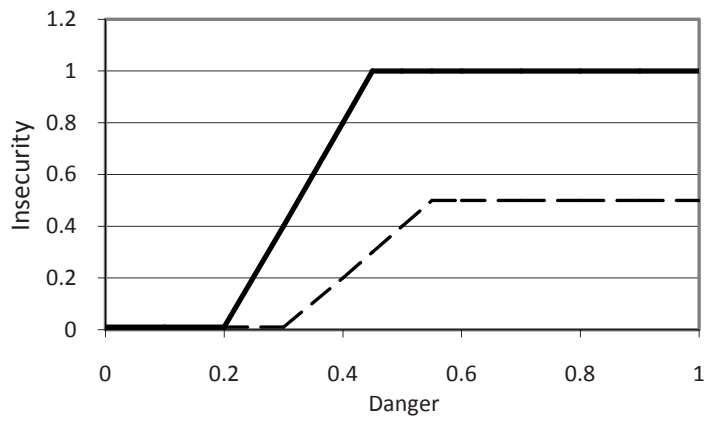

Fig. 3. Two sample Danger-Insecurity Functions

assume that it will protect itself in proportion to its sense of insecurity. So, if its insecurity is 0.6 , it will allocate $60 \%$ of its resources for protection. Then if it is a [ $\left.\begin{array}{ll}0 & 1\end{array}\right]$ type agent, it will allocate the remaining resources to production and if it is a [ 10$]$ type agent, it will predate using the rest of its resources. Now the question is about the [1 1] agent who both produces and predates. For making another connection between the personal attributes of an agent and its decision we have decided to allow [1 1 ] agents to be able to predate and produce as below, which means our agent predates more when it has a greater appetite for risk:

$$
\begin{aligned}
& \text { Predation }=(1-\text { insecurity }) .(1-c) \\
& \text { Production }=(1-\text { predation })
\end{aligned}
$$

The final features are the learning and optimization processes which are presented in Figure 4. Each agent's strategy can be mutated every five years on average (the probability is one in 260 weeks).

If its strategy is set to [0 0$]$ it will do nothing for one round and then it will continue its previous strategy. The agents keep a history of their best outcomes and associated strategies over time so they always know which strategy has been the most advantageous. During each run there may be a cross-over between its best and its current strategy. The probability of crossover can be set by the modeler and we allow agents to revise their strategies every year.

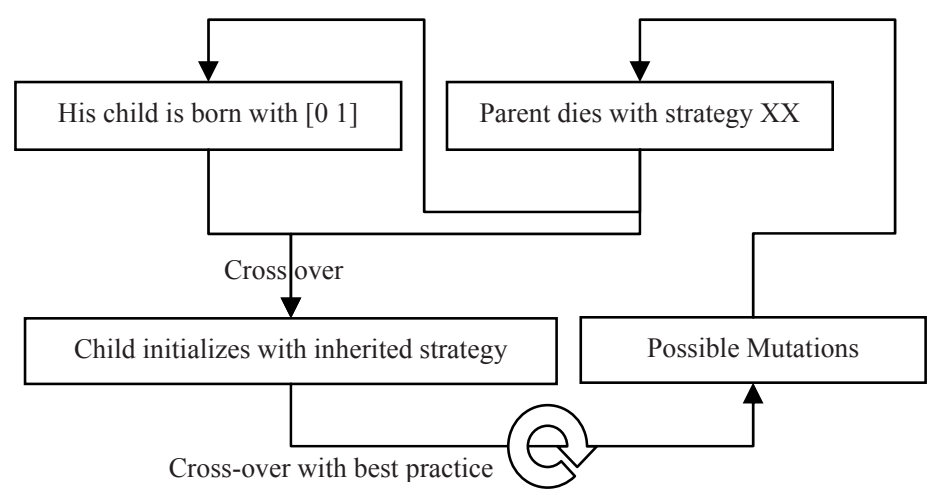

Fig. 4. The complete cycle of an agent's strategy selection and optimization 


\section{Results}

We implemented the model using NetLogo 4.0.3. Table 1 presents the main initial and control variables which we have used.

Table 1. The Specifications of the sample model

\begin{tabular}{|l|l|l|l|}
\hline Number of Agents & 100 & Available Places & 150 \\
\hline Mean of M-Age & 20 & Variance of M-Age & 5 \\
\hline Weekly Consumption & 1 & Average \# Neighbours & 4 \\
\hline Mutation Probability / Round & 0.0020 & Initial Wealth & 1 \\
\hline Initial Type of Agents & {$[01]$} & Resources & 10 (Constant) \\
\hline a (random distribution) & $(0.5,0.15)$ & b (random distribution) & $(1.5,0.15)$ \\
\hline c (random distribution) & $(0.5,0.15)$ & Pop Growth Rate & 0 \\
\hline Death Wealth Condition & $<=0$ & Probability of Crossover & $0.5 /$ bit \\
\hline
\end{tabular}

Implementing the model and executing a sample run 50 times, we have found some emergent and adaptive behaviour that cannot be captured in classic P\&C models. The first result that can be considered is the tendency of different types of models to select different strategies. The results show that usually agents with lower productivity and higher appetites for risk are more interested in allocating their resources to predation, which seems to be close to what happens in real-world societies. For example, according to our outputs, on average around $65 \%$ of agents who allocate more than $50 \%$ of their resources to predation are risk-takers and the effectiveness of their predation is more than 0.5 .

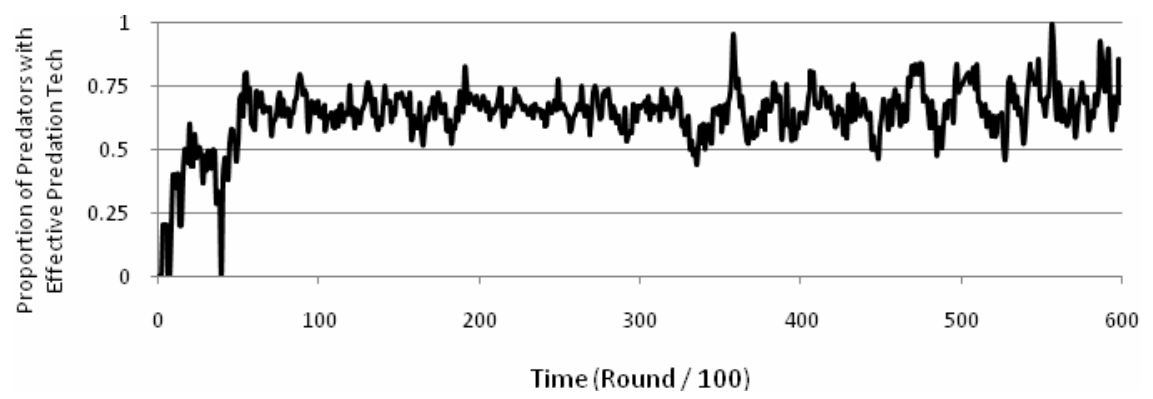

Fig. 5. A sample run. Proportion of predators with effective predation technology is usually consists more than $50 \%$ of the predators.

Figure 5 shows the percentage of agents with effective predation technologies who allocate more than $50 \%$ of their resources to predation. The observation has been made every 100 rounds to avoid unnecessary fluctuations and variations in the diagram. As can be seen, the model did not reach a stable situation for around 50 observations but we have used them in drawing the curve to present all the data. 
The other observation which shows adaptive decisions is the reaction of agents to increases in returns to production. As we expected, when returns to production become more than returns to predation, there is a sudden rise in the ratio of resources allocated to predation. Consequently, as some productive agents allocate more to predation, the production growth rate decreases. This result may not be captured using classic models easily as it happens based on the interaction of agents. Two samples are shown in figure 6 .
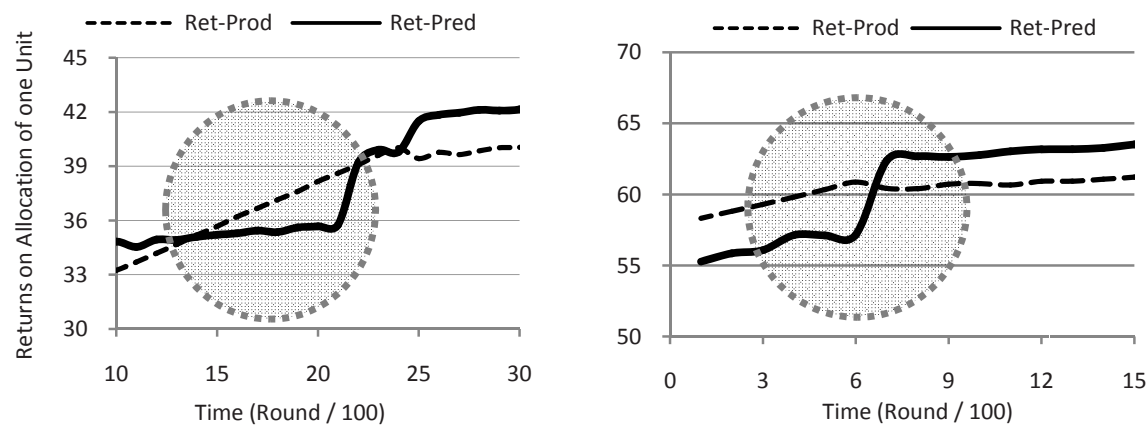

Fig. 6. Two sample runs. Ret-Prod: Return to Production. Ret-Pred: Return to Predation. As can be seen in both diagrams when returns to production are more than returns to predation, the number of predators increases very fast which causes sudden returns to predation and decrease in returns to predation.

In a long-run prespective these adaptive decisions lead to a dynamic cyclic variation which continuously happens in allocation processes. Figure 7 shows that constant consideration of returns and optimization of strategies by agents avoids any domination by a specific strategy even in the long run. As can be seen, although the diagram shows the average results for 10 runs, the cyclical allocation of production and predation resources is centred around the $40 \%$ line. The remaining resources are allocated to protection, which is not shown here. Figure 8 shows more details about the production and predation average allocation data.

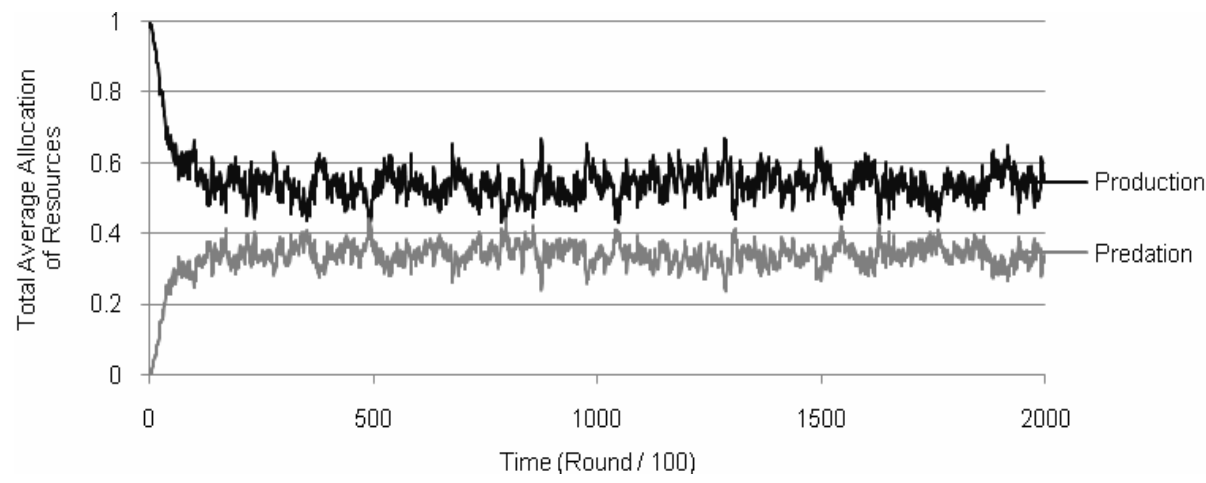

Fig. 7. A sample cyclic variation of average resource allocation in 10 runs simulation 


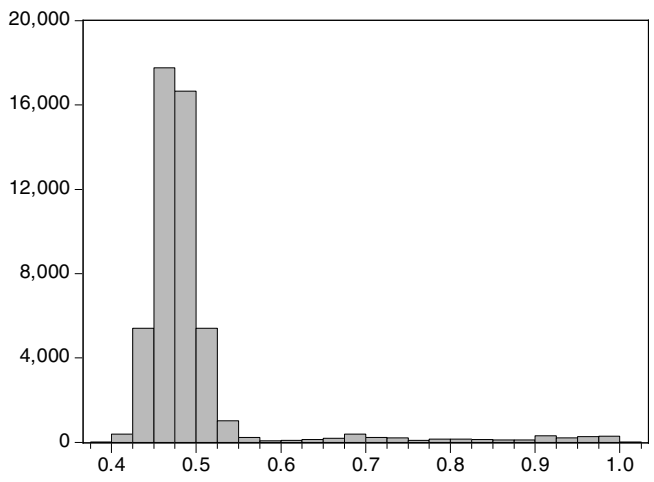

Series: PRODUCTION

Sample 150000

Observations 49999

Mean

0.496484

Median $\quad 0.476751$

Maximum $\quad 1.000000$

Minimum $\quad 0.389910$

Std. Dev. $\quad 0.088410$

Skewness $\quad 3.885574$

Kurtosis $\quad 18.61198$

Jarque-Bera $\quad 633580.3$

Probability $\quad 0.000000$

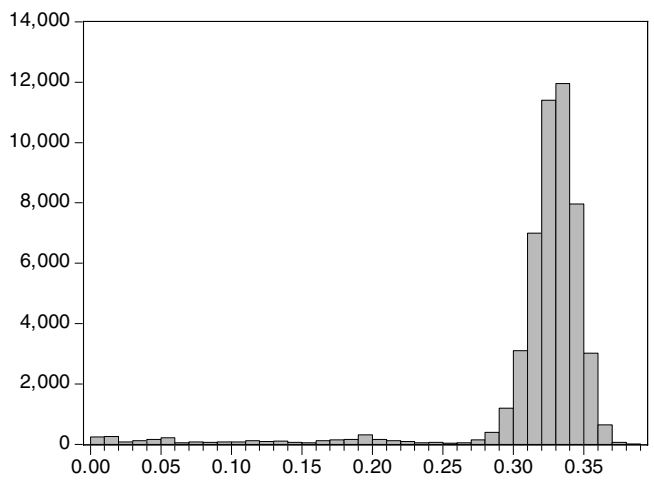

Series: PREDATION

Sample 150000

Observations 49999

Mean

Median

0.316394

0.328865

Maximum $\quad 0.383291$

Minimum $\quad 0.000000$

Std. Dev. $\quad 0.056317$

Skewness $\quad-3.867033$

Kurtosis $\quad 18.56880$

Jarque-Bera $\quad 629577.5$

Probability $\quad 0.000000$

Fig. 8. Statistical Analysis of Production Series and Predation Series

Based on reviewers' suggestion we also run another type of the model where newborn agents directly inherit their parent strategy with a following mutation with the probability of 0.5 for each bit. The observations can be shown as below:

\begin{tabular}{|ll|}
\hline \multicolumn{2}{|l|}{ Series: PREDATION } \\
Sample 1 50000 \\
Observations & 49999 \\
& \\
Mean & 0.396120 \\
Median & 0.402937 \\
Maximum & 0.461822 \\
Minimum & 0.000000 \\
Std. Dev. & 0.048559 \\
Skewness & -6.035172 \\
Kurtosis & 44.41935 \\
& \\
Jarque-Bera & 3877539. \\
Probability & 0.000000 \\
\hline
\end{tabular}

\begin{tabular}{|ll|}
\hline \multicolumn{2}{|l|}{$\begin{array}{l}\text { Series: PRODUCTION } \\
\text { Sample 1 50000 } \\
\text { Observations }\end{array}$ 49999 } \\
& \\
Mean & 0.372336 \\
Median & 0.361279 \\
Maximum & 1.000000 \\
Minimum & 0.275583 \\
Std. Dev. & 0.076040 \\
Skewness & 6.142672 \\
Kurtosis & 45.00874 \\
& \\
Jarque-Bera & 3990886. \\
Probability & 0.000000 \\
\hline
\end{tabular}

Fig. 9. The results from 10 run simulation with direct inter-generational transfer 
The results illustrate that inter-generational transfer of strategy among the agents based on our definition in this paper can decrease the intensity of predation in our environment. As an application, if we think about the transfer as an external means like effective education, the results of a 10 run simulation shows that on average, production allocated resources may increase from $37 \%$ to $49 \%$ - a $32 \%$ increase and at the same time the same index for predation decreased from $39 \%$ to $31 \%$. So, finding an useful method for preventing conflict-based behavior from being inherited by children can lead to more production and economic growth.

\section{Conclusions and Suggestions}

While the classic Production and Conflict models usually concentrate on physical aspects of the theory like technologies of production and predation and recognize them as the most effective factors when an agent makes its allocation decisions, we have attempted to also consider some new features in these models.

Our results show that our simulated agent is responsive to its environment signals and optimizes its decision according to the other agents which it knows and also its own characteristics and initial conditions. The decisions are made at the local level in our simulation based on our definitions of the neighborhood, which makes the analysis closer to real-world events.

Using an agent-based approach, we have been able to make the agents more interactive, which led to emergent behavior and more adaptive decision making compared with classic P\&C agents, which have been studied using their aggregate performance.

In general terms, in this paper we showed that in a simulated environment where there are no property rights, a significant proportion of resources will be allocated to unproductive activities which will not be useful for economic growth.

The agent designed here and its associated environment can be extended for use in different theoretical and applied areas such as the estimation of resources wasted in economic conflict and rent-seeking models, assessing the efficiency of different methods for simulating economic expectations, and modelling collective behavior, especially regarding protection and conflicts over natural resources.

\section{Acknowledgement}

The authors thank anonymous referees of this conference for their useful comments.

\section{References}

1. Hausken, K.: Production and Conflict Models versus Rent-Seeking Models. Public Choice 123(1/2), 59-93 (2005)

2. Hirshleifer, J.: The analytics of continuing conflict. Synthese 76(2), 201-233 (1988)

3. Hirshleifer, J.: Conflict and rent-seeking success functions: Ratio vs. difference models of relative success. Public Choice 63(2), 101-112 (1989) 
4. Garfinkel, M.R., Skaperdas, S.: The political economy of conflict and appropriation. Cambridge University Press, New York (1996)

5. Garfinkel, M.R., Skaperdas, S.: Economics of Conflict: An Overview. In: Sandler, T., Hartley, K. (eds.) Handbook of Defense Economics: Defense in a globalized world, Elsevier, Amsterdam (2007)

6. Grossman, H.I.: Producers and Predators. Pacific Economic Review 3(3), 169-187 (1998)

7. Grossman, H.I., Kim, M.: Swords or Plowshares? A Theory of the Security of Claims to Property. The Journal of Political Economy 103(6), 1275-1288 (1995)

8. Grossman, H.I., Kim, M.: Predation and accumulation. Journal of Economic Growth 1(3), 333-350 (1996)

9. Hirshleifer, J.: The dark side of the force: economic foundations of conflict theory. Cambridge University Press, Cambridge (2001)

10. Skaperdas, S.: Cooperation, Conflict, and Power in the Absence of Property Rights. The American Economic Review 82(4), 720-739 (1992)

11. Skaperdas, S., Syropoulos, C.: The Distribution of Income in the Presence of Appropriative Activities. Economica 64(253), 101-117 (1997)

12. Annen, K.: Property Rights Assignment: Conflict and the Implementability of Rules. Economics of Governance 7(2), 155-166 (2006)

13. Hafer, C.: On the Origins of Property Rights: Conflict and Production in the State of Nature. Review of Economic Studies 73(1), 119-143 (2006)

14. Kolmar, M.: Goods or resource contests? Public Choice 131(3), 491-499 (2007)

15. Kolmar, M.: Perfectly Secure Property Rights and Production Inefficiencies in Tullock Contests (cover story). Southern Economic Journal 75(2), 441-456 (2008)

16. Smith, J.M., Price, G.R.: The Logic of Animal Conflict. Nature 246(5427), 15-18 (1973)

17. Anderton, C.H.: Conflict and Trade in a Predator/Prey Economy. Review of Development Economics 7(1), 15-29 (2003)

18. Skaperdas, S.: Conflict and Attitudes Toward Risk. The American Economic Review 81(2), 116-120 (1991)

19. Anderton, C.H., Anderton, R.A., Carter, J.R.: Economic activity in the shadow of conflict. Economic Inquiry 37(1), 161-166 (1999)

20. Vanderschraaf, P.: War or Peace?: A Dynamical Analysis of Anarchy. Economics and Philosophy 22(02), 243-279 (2006)

21. Romer, D.: Advanced macroeconomics. Mass. McGraw-Hill, Boston (2006)

22. Muthoo, A.: A model of the origins of basic property rights. Games and Economic Behavior 49(2), 288-312 (2004)

23. Grossman, H.I., Kim, M.: Predators, moral decay, and moral revivals. European Journal of Political Economy 16(2), 173-187 (2000)

24. Sánchez-Pagés, S.: On the social efficiency of conflict. Economics Letters 90(1), 96-101 (2006)

25. Grossman, H.I.: The Creation of Effective Property Rights. The American Economic Review 91(2), 347-352 (2001)

26. Meza, D.d., Gould, J.R.: The Social Efficiency of Private Decisions to Enforce Property Rights. The Journal of Political Economy 100(3), 561-580 (1992) 